Eur J Plast Surg (1991) 14:212-218

\title{
Free muscle transplantation for treatment of facial palsy
}

\section{First experiences with the International Muscle Transplant Registry}

\author{
M. Frey ${ }^{1}$, D. Sing ${ }^{2}$, K. Harii ${ }^{3}$, L. Hakelius ${ }^{4}$, Th. Stevenson ${ }^{5}$, G. Freilinger ${ }^{6}$, J.-P.A. Nicolai ${ }^{7}$ and Ch. Sing $^{8}$ \\ ${ }^{1}$ Division of Hand-, Plastic and Reconstructive Surgery, University of Zürich Medical School, Zürich, Switzerland \\ ${ }^{2}$ Department of Physiology, ${ }^{5}$ Department of Surgery and ${ }^{8}$ Department of Human Genetics, University of Michigan, Ann Arbor, \\ Michigan, USA \\ ${ }^{3}$ Department of Plastic Surgery, University of Tokyo, Japan \\ ${ }^{4}$ Department of Plastic Surgery, Akademiska Sjukhuset, Uppsala, Sweden \\ ${ }^{6}$ Department of Plastic and Reconstructive Surgery, Second Surgery University Clinic, Vienna, Austria \\ ${ }^{7}$ Centrum voor Plastische en Reconstructieve Chirurgie, Arnhem, The Netherlands
}

Summary. Facial palsy is treated by many different operative procedures. In addition, factors such as the varying degree of paralysis, make postoperative comparisons difficult. The limited number of patients treated by free muscle transplantation at any one center also complicates evaluation of alternative treatments. This limitation has been overcome by development of an International Muscle Transplant Registry for collection, storage and analysis of data from different centers. As of June 1, 1988, 137 patients from 6 countries have been entered into the Registry. Significantly more USA/European patients had a congenital deficit and significantly more Japanese patients had a deficit resulting from surgery. According to a modification of the paresis scoring system proposed by Stennert et al. [3], USA/European patients also had a higher degree of nonsurgical facial paresis than Japanese patients. The most frequent preoperative treatment used in Japan was electrostimulation in $24 \%$ of cases, only $6 \%$ of European and American patients received this treatment. Evaluation of surgical procedures performed by the 2 groups of surgeons showed similar dimensions of muscle grafts used in the face, with a length of about $8.5 \mathrm{~cm}$ and a width of $3.4 \mathrm{~cm}$. The extensor digitorum brevis muscle was the most popular, being used in $58 \%$ of European and American cases, whereas the Japanese choice was the gracilis muscle in $94 \%$ of cases. The length of the nerve graft used by Japanese surgeons was $6 \mathrm{~cm}$, longer than that used by European and American surgeons. At this time, these preliminary data suggest evidence for paresis improvement in $79 \%$ of patients overall. Ultimately, the Registry should permit evaluation of the efficacy of different operative techniques and should influence experimental research and clinical application of muscle transplantation.

Address for correspondence. Prof. Dr. M. Frey, Klinik für Hand-, Plastische und Wiederherstellungschirurgie, Universitätsspital, Rämistrasse 100, CH-8091 Zürich, Switzerland
Key words: Facial palsy - Skeletal muscle - Free muscle transplantation - International Muscle Transplant Registry

There is a need for a systematic evaluation of the various types of facial muscle transplantation. Since Thompson [4] published his first studies using free muscle transplantation for the treatment of facial palsy in 1971, many technical modifications have been initiated. Harii in 1976 [1] added another variation when he reported the use of a free microvascular muscle transplant. Difficulties arise in comparing postoperative functional results, even when patients have similar deficits.

The lack of a satisfactory explanation for the variability arises in part from the small number of patients treated at any one center. In addition, surgeons have frequently used a number of modifications of the grafting procedure with differences in: 1) numbers of cross-face nerve grafts; 2) techniques for nerve repair; 3) mass, fiber type, and pennation of donor muscles; 4) sculpturing of donor muscles; and 5) resting tension placed on the graft by sutures. Similarly, during the postoperative period grafts may or may not be exposed to the procedures of debulking, inreasing resting tension by reducing graft length, and rehabilitative exercise. No systematic studies have been implemented to identify the specific contribution of any of these operative or postoperative procedures on the degree to which control values of structural and functional properties are recovered following grafting.

In single center studies, the small number of cases handled, coupled with the variability introduced by the requirement to adapt operative procedures to individual patient needs precludes the identification of the underlying mechanisms responsible for the excessive variability in the function of grafts transplanted into the face. In an attempt to resolve the factors that contribute to the 
variable results reported for cross-face nerve grafts and free whole muscle grafts transplanted into the face to treat unilateral facial paralysis, an International Registry for Skeletal Muscle Transplantation was developed in the Department of Human Genetics, at The University of Michigan Medical Center in 1985 and transferred to the Department of Hand-, Plastic- and Reconstructive Surgery, University Hospital, Zürich in 1990. The underlying philosophy is that an understanding of the biology of whole muscle transplantation can best be achieved through cooperative studies initiated by basic sience and clinical investigators. Furthermore, the submission of operative and postoperative data on the procedures used and the results achieved from a number of centers provides the possibility of a sufficient data base to resolve some of the unresolved issues.

The evaluation system for the facial motor function should be reduced to a few easily measured traits to make it applicable to all patients being assessed by different investigators. To this end, a standardized system for the collection, storage and analyses of data from patients with facial palsy who have been treated with free muscle transplantation has been developed. Data are being collected in a standardized format from six different centers. This paper describes the International Muscle Transplant Registry (IMTR) and gives a summary for patients entered as of June 1, 1988. The discussion will focus on some general inferences about patients who have received free muscle transplants, the procedures used in the operations, the limitation of such an international collaborative study, and the implications of our finding for future research and treatment of facial palsy.

\section{Materials and methods}

\section{Data collection instruments}

Surgeons from 6 countries are participating in this study: Austria, Japan, Netherlands, Sweden, Switzerland, and the United States; this has necessitated the development of standardized data collection forms. The content and format of these forms based on the experience and recommendations of the participating surgeons and other experts in the field of muscle transplantation. The forms consist of five different parts: The "General history/physical summary", the "Deficit evaluation history", the "Paresis assessment", the "Associated physiological abnormalities" and the "Operative notes".

In the "General history and physical summary", the identification code of the patient, age, gender, race, weight at entry into the study, and information about family history of facial paralysis are recorded. Data on the patient's medical history, such as heart disease, high blood pressure, diabetes, malignancy and smoking habits are also described. Abnormalities unrelated to the facial palsy, which are reported by the patient and by the interviewer, are evaluated for the different organ systems.

The "Deficit evaluation history" records the laterality of the deficit, its cause, the time elapsed since the onset, the physical change, and the previous treatment. The latter includes the type of operation, if any, and any other kind of treatment, e.g., electrostimulation.

The static and motor functions of the paralyzed side of the face were evaluated using a modification of the system proposed by Stennert et al. [3]. This scoring system provides the basis for the design of the "Paresis assessment" form (Table 1). Recording facts,
Table 1. Paresis scoring system for facial palsy adapted from $E$. Stennert, C.M. Limberg and K.P. Fentrup. 4 of the 10 criteria $(40 \%)$ are for the resting score and 6 for the motility score. The total number of negative findings equals the paralysis score

Region Deficit True False

\section{Resting}

Eye

1. Difference between palpebral fissures is $3 \mathrm{~mm}$ or greater

2. Ectropion is present

Mouth 3. Nasolabial sulcus is absent

4. Corner of mouth is $3 \mathrm{~mm}$ or more lower on paralyzed side

Resting paresis score $=$ sum of all true responses from questions 1-4

Motility

Fore- $\quad 5$. Affected brow motion is head less than $50 \%$ of normal side

Eye $\quad 6$. Eyelids will not close lightly as in sleep

7. Eyelids will not close tightly

Mouth 8. Upon widely showing teeth the canine teeth are not visible

9. Upon widely showing teeth the lateral upper incisor is not visible

10. Decrease of distance from paretic commissure to philtrum when pressing lips is less than $50 \%$ of that on normal side

Motility paresis score $=$ sum of all true responses from questions $5-10$

Total paresis score the presence of ectropion or of the nasolabial fold, the position of the corner of the mouth compared to the healthy side, closure of the eyelids, the ability to show different teeth, a simple and reproducible method of functional assessment which does not need excessive technical instrumentation to implement can be established. This is applicable in daily clinical practice by the different investigators. A true response was recorded as a numerical score of one and a false response as zero. Finally, a resting paresis score (sum of true responses, items 1-4) and a motility paresis score (sum of true responses, items 5-10) give a numerical outcome that may be used for the comparison of preoperative with postoperative evaluations of the same patient and/or comparisons between different groups of patients. Stennert's paresis scoring system was selected from the different systems proposed in the literature [3]. This regional system allows assessment of the differences and changes in the various facial regions. In the majority of patients, only one region of the paralyzed side of the face is treated by muscle transplantation. As with the priority of surgical correction, the system used compares rest and motion in different regions of the face. It considers the face at rest, weighted at $40 \%$ and motion, weighted at $60 \%$. The frontalis division is weighted at $10 \%$, the eye at $40 \%$ and the mouth at $50 \%$.

As associated physiological abnormalities, the presence of the corneal reflex and hyperacusis, impairment of gustation, synkinesia, generalized blink reflex, contractures, lacrimation and crocodile tears are assessed.

One part of the "Operative notes" reports details of cross-face 
nerve grafting, the second part concerns muscle transplants. Data on the number of operations, the number of nerve grafts, the donor nerves, the length of grafts, the number of fascicles in the graft and in the facial nerve branch, the route of the grafts, the technique and quality of nerve repair, and the surgeon who performed the nerve graft are included. The muscle grafts are documented in a similar fashion. Included is a description of the muscle nerve (number of fascicles, distance from nerve suture to muscle), the size and mass of muscle in situ and in the grafted site, the donor site of the graft, predenervation and the function of the muscle which is replaced by the muscle graft. All details of the operative technique are entered into the Registry database. For the arterial and venous anastomoses, the type of anastomoses, the period of ischemia and the number and diameter of vessels repaired are recorded. For the nerve repair between nerve graft and muscle nerve, the number of fascicles, the type of repair and the size of the sutures used are recorded. If additional procedures are used, e.g., reversal of fascial or muscle sling, reversal of tarsorrhaphy or canthoplasty, removal of implants, facial skin excision, these are recorded.

\section{Protocol for data collection}

The surgeons report data on standardized forms. The forms for "General history/physical summary", "Deficit evaluation history", "Paresis assessment" and "Associated physiological abnormalities" are filled out preoperatively. The form "Operative notes" is completed postoperatively. Data collection for "Paresis assessment" and "Associated physiological abnormalities" is repeated at each postoperative visit. The postoperative visits are scheduled at $6,12,18,24$ and 36 months after the last muscle graft operation. All data collection forms are sent to the Department of Human Genetics at the University of Michigan, Ann Arbor, Michigan, USA, for entry into the IMTR database. At the initial data entry, a print-out is produced in the format of the data collection forms. The resultant print-out for a given patient notes where responses are missing from the original data collection form. These print-outs are returned to the surgeons to be updated when possible. The coordinator of the Registry works with the surgeon to obtain a complete data record for the subject.

\section{Organization of the computer database}

A microcomputer (IBM AT) is used to store, access, and manipulate data in the Registry database. The software has been written in dBase III, which facilitates the creation of command files that enable the user to easily access data stored in 5 separate dBase III databases, each corresponding to one of the data collection forms. The dBase III program is menu-driven. By selecting options from appropriate menus displayed on the computer screen, one can operate particular functions of the software package. Updates to the dBase software to accommodate changes in the data collection instruments or to improve operative convenience are easily made.

A special computer program has been developed to keep track of the scheduling and collection of the paresis assessments. This program builds a database that records the history of paresis assessments for every patient for each surgeon. It is used to periodically generate a report for the surgeon that gives the schedule of assessments for each patient and notes the completed assessments.

The computer programs to manage the patient information database have been installed at two clinics. Eventually, these programs will be installed in all participating clinics to enable each collaborator to manage his own data and provide computerized transmittal of data to the IMTR in Ann Arbor.

\section{Electronic communications system}

In order to facilitate rapid exchange of information across great distances, the Bitnet telecommunications system is being used be- tween Ann Arbor, Vienna, and Uppsala. All participating surgeons have the opportunity to be linked by this system to the data management operation in Ann Arbor and to communicate independently between each other. In addition, a telephone accessed Fax system is used regularly to facilitate quick mail.

\section{Results}

\section{Description of patients}

On June 1, 1988, data on 137 patients had been registered with the IMTR. This sample included 64 males ages 6-65 years, and 73 females ages 5-69 years (Fig. 1). The sample of patients included 49 from the United States and Europe and 88 from Japan. Complete information about affected side, previous treatment, cause of deficit, and type of muscle grafted was available on $33 \mathrm{USA} /$ European and 79 Japanese patients. Table 2 shows that significantly more Japanese males are affected with facial palsy on their left sides than females $\left(X^{2}=5.8, \operatorname{Pr}<0.02\right)$.

\section{Distribution of preoperative clinical variables}

More than half of the patients (62 of 112) had no previous treatment (Table 3 ). Former operations included many different procedures. A significantly greater percentage of the Japanese patients (24\%) than USA/European patients $(6 \%)$ had received electrostimulation $\left(X^{2}=37.8, \operatorname{Pr}<0.002\right)$. Significantly more USA/European $(39 \%)$ than Japanese patients $(15 \%)$ had a congenital cause (Table $4, X^{2}=8.1, \operatorname{Pr}<0.005$ ). In significantly

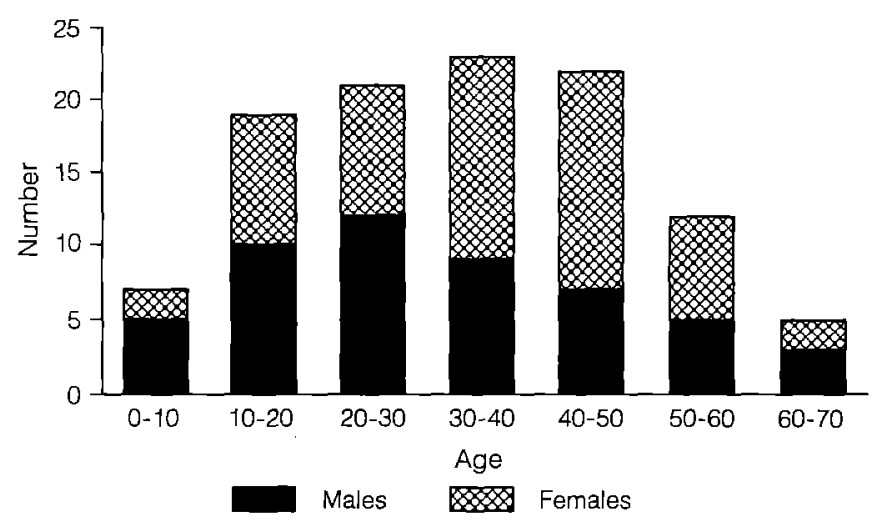

Fig. 1. Age distribution at time of muscle graft operation $(n=112)$

Table 2. Laterality of facial palsy by sex of patients $(n=112)$

\begin{tabular}{lccccccc}
\hline $\begin{array}{l}\text { Affected } \\
\text { side }\end{array}$ & \multicolumn{2}{l}{ USA/European } & & \multicolumn{2}{l}{ Japanese } & \\
& Males & Females & Totals & Males & Females & Totals \\
\hline Right & 5 & 10 & 15 & 16 & 28 & 44 \\
Left & 8 & 10 & 18 & 23 & 12 & 35 \\
Total & 13 & 20 & 33 & 39 & 40 & 79 \\
\hline
\end{tabular}


Table 3. Distribution of previous treatment $(n=112)$ European and USA surgeons/Japanese surgeons

\begin{tabular}{lccc}
\hline First previous treatment & Males & Females & Total \\
\hline Electrostimulation & $0 / 11$ & $2 / 8$ & $2 / 19$ \\
Fascial sling & $1 / 0$ & $1 / 0$ & $2 / 0$ \\
Muscle sling & $0 / 0$ & $2 / 0$ & $1 / 0$ \\
Eyelid procedures-tarsorrhaphy & $2 / 0$ & $2 / 2$ & $4 / 2$ \\
Eyelid procedures-canthoplasty & $0 / 1$ & $0 / 0$ & $0 / 1$ \\
Eyelid procedures-implants & $0 / 0$ & $0 / 0$ & $0 / 0$ \\
Facelift & $0 / 0$ & $0 / 2$ & $0 / 2$ \\
Myotomy on normal side & $0 / 0$ & $0 / 0$ & $0 / 0$ \\
Neurotomy or neurectomy & $0 / 1$ & $0 / 0$ & $0 / 1$ \\
Other procedures ${ }^{2}$ & $3 / 6$ & $1 / 6$ & $4 / 12$ \\
None & $7 / 20$ & $12 / 22$ & $20 / 42$ \\
\cline { 2 - 4 } Total & $13 / 39$ & $20 / 40$ & $33 / 79$
\end{tabular}

a Other procedures include: Andersen's operation, hypoglossalfacial nerve cross-over, massage, nerve block, medication, acupuncture, stainless steel sling, cholesteatomectomy

Table 4. Historic cause of deficit $(n=112)$

\begin{tabular}{lccr}
\hline Cause of deficit & $\begin{array}{l}\text { USA/European } \\
\text { patients }\end{array}$ & $\begin{array}{l}\text { Japanese } \\
\text { patients }\end{array}$ & Total \\
\hline Congenital & 13 & 12 & 25 \\
Trauma-extracranial & 1 & 2 & 3 \\
Trauma-intracranial & 2 & 2 & 4 \\
Bell's palsy & 0 & 2 & 15 \\
Poliomyelitis & 1 & 26 & 3 \\
Surgical-extracranial & 3 & 13 & 16 \\
Surgical-intracranial & 3 & 0 & 1 \\
Malignant tumor & 1 & 2 & 6 \\
Benign tumor & 4 & 5 & 10 \\
Other cause & 5 & 79 & 112 \\
\hline
\end{tabular}

more Japanese $(33 \%)$ than USA/Europeans $(9 \%)$, the deficit was caused by extracranial surgery $\left(X^{2}=7.3, \operatorname{Pr}<\right.$ 0.01 ). For all patients, the most frequent cause was extracranial surgery $(26 \%)$, followed by congenital $(22 \%)$, intracranial surgery $(14 \%)$ and Bell's palsy $(13 \%)$. Interestingly, only in Japanese patients was Bell's palsy treated by muscle transplantation.

Preoperative paresis evaluations were available on 111 of the 112 patients described in Tables $2-4$. Although the average resting paresis score was very similar for the 2 groups, USA/European patients had a significantly greater average motility paresis score than Japanese (Table 5). No evidence for a significant association between gender and paresis score for either group of patients was observed.

\section{Description of operation received}

Information on vascular anastomoses was available on 110 of the 112 patients considered in this study. 88 of the 110 received a documented vascular anastomosis. In 83 of these 88 , reinnervation of the muscle transplant
Table 5. Preoperative paresis scores $(n=111)$

\begin{tabular}{|c|c|c|c|c|c|c|}
\hline & \multicolumn{3}{|c|}{ USA/European $(n=33)$} & \multicolumn{3}{|c|}{ Japanese $(n=78)$} \\
\hline & $\begin{array}{l}\text { Males } \\
N=13\end{array}$ & $\begin{array}{l}\text { Females } \\
20\end{array}$ & $\begin{array}{l}\text { All } \\
33\end{array}$ & $\begin{array}{l}\text { Males } \\
39\end{array}$ & $\begin{array}{l}\text { Females } \\
39\end{array}$ & $\begin{array}{l}\text { All } \\
78\end{array}$ \\
\hline \multicolumn{7}{|c|}{ Resting score } \\
\hline $\begin{array}{l}\text { Average } \\
\text { S.D. }\end{array}$ & $\begin{array}{c}1.85 \\
(1.28)\end{array}$ & $\begin{array}{c}1.95 \\
(1.00)\end{array}$ & $\begin{array}{c}1.91 \\
(1.10)\end{array}$ & $\begin{array}{c}1.97 \\
(1.14)\end{array}$ & $\begin{array}{c}1.77 \\
(0.93)\end{array}$ & $\begin{array}{c}1.87 \\
(1.04)\end{array}$ \\
\hline \multicolumn{7}{|c|}{ Motility score } \\
\hline $\begin{array}{l}\text { Average } \\
\text { S.D. }\end{array}$ & $\begin{array}{c}3.92 \\
(2.43)\end{array}$ & $\begin{array}{c}3.85 \\
(1.87)\end{array}$ & $\begin{array}{c}3.88 \\
(2.07)\end{array}$ & $\begin{array}{c}2.02 \\
(1.60)\end{array}$ & $\begin{array}{c}2.18 \\
(1.60)\end{array}$ & $\begin{array}{r}2.10^{4} \\
(1.59)\end{array}$ \\
\hline \multicolumn{7}{|c|}{ Total paresis score } \\
\hline $\begin{array}{l}\text { Average } \\
\text { Score }\end{array}$ & $\begin{array}{c}5.77 \\
(3.11)\end{array}$ & $\begin{array}{c}5.80 \\
(2.48)\end{array}$ & $\begin{array}{c}5.79 \\
(2.70)\end{array}$ & $\begin{array}{c}4.00 \\
(2.34)\end{array}$ & $\begin{array}{c}3.95 \\
(2.16)\end{array}$ & $\begin{array}{r}3.97^{\mathrm{a}} \\
(2.24)\end{array}$ \\
\hline
\end{tabular}

${ }^{a}$ USA/European scores are significantly higher than those of Japanese at the 0.001 level of probability. Scores may range from 0 to 10 . The larger the score the greater the deficit

Table 6. Muscle used for transplantation $(n=112)$

\begin{tabular}{lrrrrr} 
& $\begin{array}{l}\text { USA and } \\
\text { European } \\
\text { surgeons }\end{array}$ & $\begin{array}{l}\text { Japanese } \\
\text { surgeons }\end{array}$ & Total \\
\hline $\begin{array}{l}\text { Extensor digitorum brevis } \\
\text { Gracilis muscle }\end{array}$ & $19(0)^{a}$ & 0 & $(0)$ & 19 \\
Latissimus dorsi & 0 & $(10)$ & $74(74)$ & 84 \\
Palmaris longus & 2 & 4 & $(4)$ & 4 \\
Other $^{b}$ & 2 & $(1)$ & 1 & $(1)$ & 3 \\
\hline
\end{tabular}

a Number of grafts with vascular anastomoses given in ()

${ }^{b}$ Other: Sartorius, Extensor hallucis brevis, rectus abdominis

was by a single cross-face nerve graft. The principal differences were in the muscle transferred for the $112 \mathrm{pa}$ tients described in Tables $2-4$. In over $90 \%$ of the Japanese operations ( 74 patients), the gracilis was the muscle of choice (Table 6). Besides the gracilis muscle, the latissimus dorsi was transplanted in 4 cases, and the rectus abdominis muscle in 1 case. In the $33 \mathrm{USA} /$ European operations, the extensor digitorum brevis was used 19 times, and the gracilis muscle 10 times. Other muscles were rarely used; the palmaris longus in 2 patients, the sartorius in 1 patient and the extensor hallucis brevis in 1 patient. 90 of the 112 operations $(80 \%)$ involved vascular anastomoses. All Japanese operations and 33\% of the USA/European operations involved revascularized muscles.

Measurements of the final size of the muscle, or part of a muscle, transplanted into the face were not available on all of the 112 patients considered in Tables $2-6$. For those measured, no statistically significant differences $(\operatorname{Pr}<0.10)$ in the average length or width of the muscle for the 2 groups (Table 7) was observed. The overall average length of $8.52 \mathrm{~cm}(\mathrm{SD}=1.9)$ and a width of $3.32 \mathrm{~cm}(\mathrm{SD}=1.4)$ for all patients seems to be appro- 
Table 7. Characteristics of the cross-face nerve graft and the muscle transferred

\begin{tabular}{|c|c|c|c|c|c|c|}
\hline & \multicolumn{3}{|c|}{$\begin{array}{l}\text { European and } \\
\text { USA surgeons }\end{array}$} & \multicolumn{3}{|c|}{$\begin{array}{l}\text { Japanese } \\
\text { surgeons }\end{array}$} \\
\hline & Males & Females & All & Males & Females & All \\
\hline \multicolumn{7}{|c|}{ Length of cross-face nerve graft $(\mathrm{cm})$} \\
\hline $\begin{array}{l}\text { Average } \\
\text { S.D. } \\
n\end{array}$ & $\begin{array}{c}14.66 \\
(1.52) \\
3\end{array}$ & $\begin{array}{c}16.44 \\
(4.30) \\
9\end{array}$ & $\begin{array}{c}16.00 \\
(3.81) \\
12\end{array}$ & $\begin{array}{l}23.29 \\
(3.54) \\
17\end{array}$ & $\begin{array}{l}21.62 \\
(5.38) \\
26\end{array}$ & $\begin{array}{l}22.28^{\mathrm{a}} \\
(4.77) \\
43\end{array}$ \\
\hline \multicolumn{7}{|c|}{ Length of muscle (cm) } \\
\hline $\begin{array}{l}\text { Average } \\
\text { S.D. } \\
n\end{array}$ & $\begin{array}{l}7.00 \\
(2.64) \\
3\end{array}$ & $\begin{array}{l}7.80 \\
(3.21) \\
7\end{array}$ & $\begin{array}{l}7.56 \\
(2.92) \\
10\end{array}$ & $\begin{array}{l}8.72 \\
(1.89) \\
38\end{array}$ & $\begin{array}{l}8.56 \\
(1.74) \\
33\end{array}$ & $\begin{array}{l}8.65 \\
(1.81) \\
71\end{array}$ \\
\hline \multicolumn{7}{|c|}{ Width of muscle $(\mathrm{cm})$} \\
\hline $\begin{array}{l}\text { Average } \\
\text { S.D. } \\
n\end{array}$ & $\begin{array}{c}1.50 \\
(0.50) \\
3\end{array}$ & $\begin{array}{c}3.67 \\
(4.31) \\
7\end{array}$ & $\begin{array}{l}3.02 \\
(4.31) \\
10\end{array}$ & $\begin{array}{l}3.40 \\
(0.62) \\
35\end{array}$ & $\begin{array}{l}3.34 \\
(0.60) \\
32\end{array}$ & $\begin{array}{l}3.37 \\
(0.60) \\
67\end{array}$ \\
\hline
\end{tabular}

a Average length of nerve used by Japanese surgeons was significantly greater than those used by European and USA surgeons at the 0.001 level of probability

priate for a facial muscle graft. The average length of the nerve graft (Table 7) used by the Japanese, $22.28 \mathrm{~cm}$, was significantly longer than that used by Europeans and Americans, $16.00 \mathrm{~cm}$. No evidence for an association between gender and size of muscle used or length of nerve graft was observed for either USA/European or Japanese patients. These data suggest that the relationship between length of muscle nerve and length of nerve graft used by the 2 groups was somewhat different.

\section{Postoperative improvement of paresis score}

Because the majority of the patients entered into the Registry as of June 1, 1988 provide only retrospective data, many are missing several of the paresis assessments provided by the follow-up protocol. One or more assessments were available on each of the 112 patients considered here. Only a few patients were evaluated at all time periods. All but one patient had a preoperative paresis evaluation.

The average paresis scores of those measured during each time period are summarized in Fig. 2. Postoperative resting scores showed greatest improvement during the first 12 months. Patients who were evaluated thereafter showed little improvement. On the average, the motility score did not improve until 24 months. These data suggest that the early improvement of the total paresis score is attributable to improvement of resting scores while improvement after two years is attributable to improvement of motility scores.

Table 8 compares the average postoperative scores collected at each time period on subgroups of the $112 \mathrm{pa}-$ tients with their corresponding average score for the preoperative evaluation. In contrast to the averages based on all data presented in Fig. 2, the 30 patients evaluated at preop and at 6 months show a statistically significant improvement in their total score. This was primarily at-

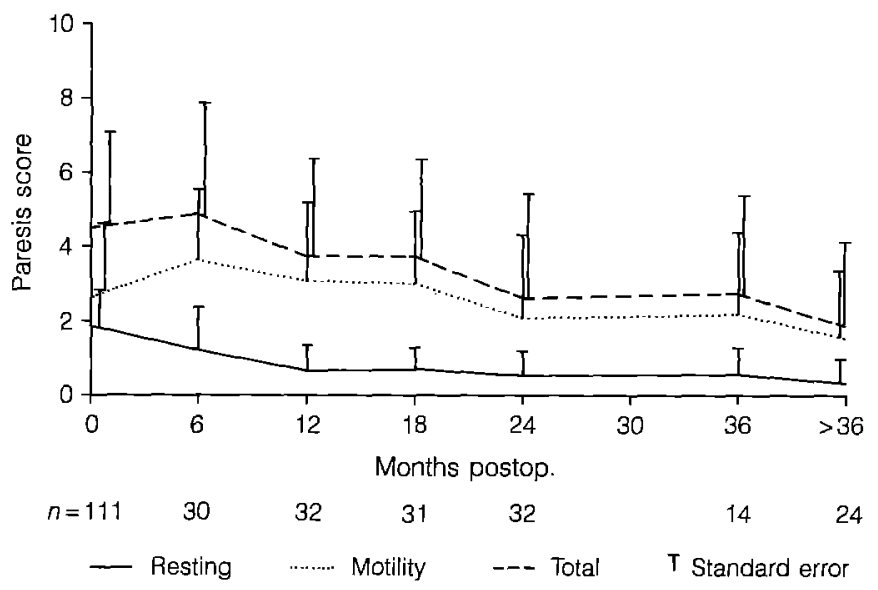

Fig. 2. Mean of paresis scores ( \pm standard deviation) for all assessments at the different time points after free muscle transplantation for the treatment of facial palsy. Patients included $(n=72)$ had at least one muscle graft operation, a preoperative paresis assessment and at least one postoperative paresis assessment

Table 8. Improvement at specific time points (average at each time point minus preoperative average)

\begin{tabular}{lllll}
$\begin{array}{l}\text { Time } \\
\text { point }\end{array}$ & $n$ & Resting & Motility & Total \\
\hline 6 Month & 30 & -0.23 & $-0.53^{* *}$ & $-0.77^{*}$ \\
12 Month & 32 & $-1.38^{* * *}$ & $-0.84^{*}$ & $-2.22^{* * *}$ \\
18 Month & 30 & $-1.53^{* * *}$ & -0.67 & $-2.20^{* * *}$ \\
24 Month & 32 & $-1.63^{* * *}$ & $-1.06^{* * *}$ & $-2.69^{* * *}$ \\
36 Month & 14 & $-1.29^{* * *}$ & $-1.49^{*}$ & $-2.36^{* * *}$ \\
$>36$ Month & 24 & $-1.38^{* * *}$ & -0.54 & $-1.92^{* *}$ \\
\hline Significance: & & & & \\
$*=<0.05$ & & & & \\
$* *=<0.01$ & & & \\
$* * *=<0.001$ &
\end{tabular}

tributable to a small improvement in motility score. There was highly statistically significant evidence for improvement of the total paresis score regardless of the time lag until the postoperative evaluation. The analyses presented in Table 8 further support the inference that most of the improvement in resting scores occurs in the first 12 months and that motility scores did not show improvement until 24 months after the operation. When combined into the total score, it is apparent from these data that little improvement in the patients overall paresis evaluation occurred after 24 months.

\section{Discussion}

Patients registered in the IMTR thus far show no association between age, race and gender or between time of the first muscle graft operation and whether they were USA/European or Japanese. No explanation was found for the observed excess of male Japanese with partial left-sided facial paralysis. Although no evidence was observed for a significant association between the first previous treatment and gender, a significantly large number of Japanese patients had electrostimulation. Preoperative treatment depends largely on the specialty treating 
the patient before surgery and is not a consequence of patient selection by the surgeon. Conservative treatment regimes vary considerable, especially in this international study.

Surprisingly, the cause of the palsy in USA/European patients was predominantly congenital $(39 \%)$ whereas in Japanese patients it was extracranial surgery $(33 \%)$.

Although no significant association was found between gender and preoperative paresis scoring for either group, significantly greater motility scores were reported for USA/European patients. The facial palsies treated by muscle transplantation seem to be more pronounced in USA/European patients. The lower motility score in Japanese patients is caused by a higher incidence of incomplete or partial facial palsies in this group. Patients with left-sided involvement have greater motility scores than those with right-sided involvement. We have no explanation for this observation.

When patients of each group were considered separately, there was no significant association between the type of muscle used as a graft and gender. However, there was a highly significant difference between Japanese surgeons and European and United States surgeons in the type of muscle transferred. Another important difference between the groups of surgeons is the length of the cross-face nerve graft. This difference is due to different operative techniques and not the different anatomy of the muscle used. Japanese surgeons used a nerve $6 \mathrm{~cm}$ longer on average than did the European and United States surgeons. With progress of the study, perhaps the optimal operative technique can be formulated.

Improvements in the paresis score are greatest in the first 12 months following transplantation. This is particularly apparent in this study for the resting score. Motility scores showed greatest improvement beyond 18 months following the operation. These observations suggest that the paresis evaluation instrument is sensitive to detection of changes that may be occurring in resting and motility performance of patients receiving a facial transplant.

\section{Limitations of the registry}

At the moment, the majority of the 137 patients entered are retrospective. Consequently, data are incomplete for many patients resulting in considerable variability of sample size for various types of measurements, especially for postoperative evaluations. With time, there will be new cases with complete data and a complete three year IMTR follow-up thus meaningful statistics will be produced. The cooperation from participating surgeons suggests that the data collection protocol can be completed on a much larger sample of patients receiving the muscle transfer to the face. The complex functional status of the face cannot be documented adequately by a 10 point scoring system that includes a resting score as well as a motility score. Nevertheless, the facial paralysis defect score proposed by Stennert et al. [3] combines a comprehensive description of the static and dynamic function of the face with a high practicability in the situation of repeated clinical assessments of the changing function. This simple method avoids the necessity of extensive technical instrumentation. It can be used by different investigators in different geographical locations in an easily reproducible way.

\section{Implications of findings for future research and for clinical application}

At this stage of the study, many significant results have been obtained. As far as how they apply to the differences in operative techniques, experimental research could help to eliminate the complexity of relevant factors like age of patient, surgeon performing the operation and other differences in technical details of the operation. For example, the influence of the relationship between the length of the cross-face nerve graft and the length of the nerve of the muscle graft on the functional recovery of the muscle graft might be clarified in an experimental series. Within the current Registry, it is not possible to produce a group of patients large and homogenous enough to answer this question.

The experiences with the use of the data collection instruments have necessitated several changes. In addition, the use of the standardized video documentation has been discussed as an alternative method of measurement of paresis. In the future, the opinion of the patient on the improvement of his facial disability must be integrated in a more detailed way and without the influence of the treating surgeon. In the future, information from the International Muscle Transplant Registry database can be expected to influence the clinical use of muscle grafts for the treatment of facial palsy. For the present, although analysis of incomplete retrospective data suggests some interesting trends; strong inference with regard to a number of key issues must await an expanded dataset that includes complete prospective data on a representative subset of patients.

Acknowledgements. The International Muscle Transplant Registry was initiated by basic scientists, when they got contact to the clinical problems of plastic surgeons. We want to thank especially Bruce M. Carlson, M.D., Ph.D., Professor of Biologial Sciences, and John Faulkner, Ph.D., Professor of Physiology, both at the University of Michigan, Ann Arbor, Michigan, USA, for their constant input of stimulating ideas and energy into this project and for their support during the writing of this paper. This research was supported by a grant from the National Institutes of Health DEO7687.

\section{References}

1. Harii K, Ohmori K, Torii S (1976) Free gracilis muscle transplantation with microneurovascular anastomoses for the treatment of facial paralysis. Plast Reconstr Surg 57:133

2. House JW (1985) Facial nerve grading systems. In: Portmann $\mathrm{M}$ (ed) The facial nerve. Masson, New York Paris, p 35

3. Stennert E, Limberg CM, Fentrup KP (1979) Paralysis and secondary defect score. In: Miehlke A, Stennert E, Chilla R (eds) New aspects in facial surgery. Clin Plast Surg 6:458

4. Thompson N (1971) Autogenous free grafts of skeletal muscle. A preliminary experimental and clincial study. Plast Reconstr Surg 48:11 


\section{Editorial comment}

Facial palsy is a frustrating entity to treat. Each surgeon has his "pet" method; the justification for its use is usually anecdotal and frequently inaccurate. It is disappointing to see presentations which rely on enthusiastic presentation and still photographs. Only by animation provided by video can a true assessment of results be made. Dr. Frey and his colleagues are to be congratulated on many aspects of their presentation. They realize the importance of a prospective investigation but have based the design on an extensive retrospective series. The investigation is international, standardized and well controlled. They recognize the deficiencies of static displays and are investigating the use of video. Perhaps most important, they are, at least initially, limiting the investigation to muscle transplantation.

Perhaps to enable significant results to be obtained more expeditiously, other centers dealing with large numbers of patients should be invited to join in this Registry.

Ian T. Jackson, Editor-in-Chief

\section{THE SEARCH BOARD}

It has been decided to create a new section in the Journal for advertisements. This is intended to be an information source about plastic surgery fellowships which are available, or being created, and as much information about these fellowships as the director of the program would wish to insert. In addition to this, news of any other positions available, practices for sale, or partnerships available would be welcomed.

The service is free of charge; all information to be published should be sent to the Editor. 